the case of this patient, I have surmised that in cases of ordinary undoubted croupous pneumonia also there is some morbid change of the cord caused by pnenmotoxin. I suggest that the central lesion is the cause of the nonpulmonary symptioms of pneumonia, the high temperature, rapid respiration, and infrequent pulse (infrequent, I mean, only in relation to the respiration rate). I do not think the local pulmonary inflammation would produce such symptoms in such relation.

There was in Mr. Wilkin's patient a symptomatic condition (so to say, a double one) which I have never observed before in any kind of case; no doubt I have overlooked it. The patient's intercostal muscles acted not at all during his ordinary (but very frequent) breathing (respiration proper), but they acted perfectly when he drew in his breati when told to do so (voluntary movement). During respiration proper, whilst, as said, the intercostals did not act, the diaphragm acted well, perhaps in too short excursions, and also frequently; in other words the breathing of this patient was solely diaphragmatic. (The lowest part of his chest everted in inspiration -respiration proper-but the diaphragm by itself can evert the lowest ribs.) In the voluntary movement the intercostals acted well and the diaphragm not at all so far as I could make out, the epigastrium sinking; that is to say, the voluntary movement was made as a healthy adult male would make it. We see that the fact that a patient can expand his chest walls well by his intercostals when told (voluntary movement) is no proof that the other, the true respiratory movement of them, is present; in $\mathbf{M r}$. Wilkin's patient there was loss of the automatic movement with persistence of the volantary movement of the same muscles. ${ }^{1}$

The next day Dr. Barlow saw the patient with us. (Temperature, respiration, and pulse about the same as when I first saw him.) He confirmed the observations I made the previous day. I was particularly interested in his agreement that the intercostal muscles did not ast in respiration proper, and that they did act in the voluntary movement of so-called "forced inspiration."

The patient did well; his knee-jerks retarned. At no stage of his illness was there any other paralysis discovered than that signified by inaction of the intercostal muscles in respiration proper; these muscles on his recovery acted normally both respiratorily and voluntarily.

I infer, from the consideration of certain of Gaskell's most important researches, that in this patient the inaction of the intercostal muscles in respiration proper was owing to loss of function of lateral horns in the thoracic region of the cord ; if so, the respiratory (medulla) centre (the lateral horns being, I presume, for respiration proper normally subservient to that centre) failed to effect anything upon the intercostal muscles, although it continued to act on some other of its subordinate centres of the cord, those which are for the immediate supply of the diaphragm. The voluntary service of the intercostals in drawing in the breath when told (so-called "forced inspiration") is of cerebral initiation ; indeed, the word voluntary implies that. The fibres engaged in this voluntary service of the intercostals are, I suppose, some of the fibres of the pyramidal tract, which, evading the respiratory (medulla) centre, pass direct from the cortex cerebri to cells, not of the lateral horns, but to cells of the ventral part of the anterior horns, to those cells of those horns to which other fibres of the pyramidal tract go. (I think that during such voluntary, non-respiratory, services of the intercostals the respiratorymedulla-centre is inhibited by fibres from the cerebral cortex.)

The inaction of the intercostals in respiration proper--since I thought it owing to a very limited myelitis or other local morbid change of some part of the lateral horns, if not of more of the cord-makes me surmise, as has been already said, that in ordinary cases of croupous pneumonia, cases with discoverable local pulmonary disease, there is a very local central morbid change, if not of the lateral horns, as I suppose there was in Mr. Wilkin's patient, yet of some other parts of a cord district of which that tract is part. It may at any rate be worth while to search the cord and medulla microscopically of one who has died of pneumonia. We must bear in mind that Mott thinks that the intermediolateral tract is the visceral column. In later notes I shall reconsider the case of Mr. Wilkin's patient and suggest other possibilities.

1 In a case of fracture dislocation crushing the cervical cord across below the emergence of the phrenic nerves the chest walls do not move
either in respiration proper or in a non-respiratory (voluntary) service.

\section{AN INTERESTING CASE OF CEREBRAL HAMORRHAGE.}

BY HENRY T. BENSON, L.R.C.P. LOND., \&C.

THE interesting points to my mind raised in this case were as follows : the extraordinary absence of symptoms pointing to the extensive lesion and the suggestion that a sudien jerking of the head backwards might have causeci death.

The patient was a man forty-fire years of age, a farmer, slenderly built, moderately temperate, and whose facaily. history was good. On Dec. 9hh he went to a shed to give a. calf a drench; in doing so the calf plunged, and in try ing to avoid it he suddenly threw his head backwards. I 8 a w hm on Dec. 11th, and found him suffering from intense yain and rigidity of the neck, with a few tender spots nbout the occipital region. The temperatare, pulse, and pupils were normal, and with rest and light diet he appeared better, in Dec. 24th there was pain over the forehead, with tenderies over the same region, and also ats a point half an inch below and two inches to the left of the occipital protuberance. The tongue was coated; the pupils were equal and resconded both to distance and light, but showed some slight intolerance to light and sound. I looked for paralytic symptorns in the face, eyes, mouth, throat, and extremities without result. He had an uneasy feeling about the right arm, but I could not detect any motory or sensory impairment; the reflexes were normal, the pulse was well filled, regular, and not eas il compressed, 80 per minte ; the temperature was 99.20 F.; the heart was normal and the appetite fair ; be was able to sleep from five to six hours at a time naturally; the functions pexformed regularly ; he was cheerful in his manner, but said he did not feel quite so well as he had been a day or two before. I saw him again on Dec. 26 th at 8 A.M., and founc. he had just recovered from a fainting attack. The general condition was mach the same as on the $24 \mathrm{th}$, but the pulse. was 90 and rather easily compressed; the temperature was $100^{\circ}$ and the respiration 20 ; the pupils were sluggish and nystagmus was present. I ascribed his condition to straining during the passage of a hardened stool. He was conscious, bat occasionally rambled. On taking the temperature about threequarters of an hour later it had risen over a degree. There. was muscular twitching. I attempted to make a diagnosis of "concussion by succussion." On Dec. 27th the patient was in a semi-comatose condition, the urine was voided at long intervals, and the bowels moved involuntarily. The pulse was 80 and the temperature $102^{\circ}$. He had delirium of $a$ low muttering form. On the 28th his condition remained. unchanged. The urine was examined and was found to bas free from sugar and albumen. On the 29 th he was less delirious, but the twitching continued. The temperature was $101^{\circ}$. The patient was still very drowsy. On the 30 th be appeared better. The pulse was fairly good as regards volume and compressibility, and he was less drowsy. The temperature was $100^{\circ}$. On the 31 st his condition was the same as on the previous day. The temperature was $98.3^{\mathrm{m}}$ and the pulse 85 . He was conscious and resting well. The natural functions were performed consciously, and he bad not rambled since the day before. On Jan. 1st the temperature was normal and the pulse regular-80. The twitching anc nystagmus had ceased. He spoke rationally and expressed himself as feeling better. On the 2nd there was no change. On the 3 rd he had severe convulsion and suddesty becawe comatose. On Jan. 4th he died. At the necropsy, on Jan. 8th, there was no external injury or post-raortera staining. The body was well nourished. A transverse incision. was made from ear to ear, and a longitudinal incision alout the spines of the vertebræ, the skin and fascia were reflected to expose the muscles of the neck. The trapezins was normal and reflected. The splenius and sterno-mastoid were normal. The splenius was divided and reflected. The complexus was normal. There was no injury to any of the muscles. The cervical spine was cleaned; there was nolesion. 'The external ligaments appeared normal. The spinal column was opened from the second to the ninth vertebræ. The cellular tissue between the medullary sheath and the ligaments ining the spinal column were deeply stained with eztravasated blood. The blood was extravasated in the subarachnoid space. There was a laminated diffuse clot in the portion corresponding to the second, third, and fourth cervical vertebræ. There was slight subaracnoid effusion along the longitudinal fissure of the brain. On the right side there was a very superficial subarachnoid clot overlapping the frontas 
convulsion. From the back of the spinal cord the clot cou'd be traced over the medulla oblongata, the base of the cerebellum, and the bise of the brain. The clot extended into the left lateral ventricle. In the anterior left lateral lobe of the brain there was a laceration containing a elot, and the lacerated surface was slightly softened, communicating with the longitudinal fissure. There was no evidence of any disease in the surrounding parts of the brain. The laceration in the anterior portion of the left lobe of the brain appeared to be a continuation of the fissure of Sylvius, and may have been due to softening. The thorax, beart, and lungs were normal and healtby. All the organs in the abdominal cavity were healthy.

Morket Deeping.

\section{THE RESULTS OF RADICAL OPERATION FOR MALIGNANT DISEASE OF THE} LARYNX, FROM THE EXPERIENCES
OF' PRIVATE PRACTICE.

BY FELIX SEMON, M.D. BERL., F.R.C.P. LOND.,

MARESIDENT OF THE LARYAGOLOGICAL SOCIETY OF LONDON; PHISICIAN FOR DISEASES OF THE THROAT TO ST, THOMAS'S HOSPITAL, ETC.

\section{(Continued from p. 1419.)}

IN the following tables no column is devoted to the auration of the disease, because evidence on this point in a number of the cases operated upon was of an unsatisfactory or at lesst very uncertain character, and I do not wish to possibly allow erroneous opinions to be formed from the uncertain answers of the patients themselves. $\mathrm{On}$ the whole, it may be said that the minimum of time which clapsed between the first symptom-almost always hoarsemess-and the performance of the radical operation was two months, and the maximum, in one exceptional case (No. 6 . of the tables) two years. Most cases, howerer, came to operation during the first year of the disease. The results of these tables are as follows:-

1. Nature of operations and proportions of recovery.Out of twelve cases in which radical operations were performed the method was as follows:

Partial extirpation of the Rtcoveries. Deaths. Thyrotomy with resection of portions of cartilage

Thyrotomy with removal of sotc parts only... ... ... ... ... $\ldots .$.

gubhyoid pharyngotomy with re-

moval of soft parts only ... ... 1

$\begin{array}{llllll}\text { Total... } & \ldots & \ldots & \ldots & \ldots & \overline{12}\end{array}$ $4 \quad \ldots \ldots 4 \quad 4 \quad \ldots \ldots-$ $\begin{array}{llll} & \ldots & & \end{array}$ $1 \ldots \ldots-\ldots . .1$ 75

If it be assurned that the two cases in which the malignancy was doubtful (more on this point further on) actually were of a malignant natare it will be seen that 5 patients died from the consequences of the operation and 7 recovered, a result which, though at first sight apparently not, very brilliant, must be considered eminently satisfactory, as it means the saving of fally 58.3 per cent. of the patients from an otherwise inevitable death. This is certainly a most encouraging advance in our treatment of malignant disease of the lary $n x$, and so far as my knowledge goes it very considerably surpasses the results hitherto recorded. Nor, indeed, did these 583 per cent. represent the full measure of success that ought to have been obtained. In 2 of the fatal cases (Cases 4 and 6 of the tables) death was due, as will be shown later, to preventable complications in no way necesearily connected with the operative procedure itself, and had these complications been avoided the proportion of successes in my 12 cases might actually have been brought as high as 66.6 per cent. If, on the other hand, it be assumed that Case 11, the most doubtful one of the tables, was rot a case of actual malignancy we should have 11 cases with 6 recoveries, or 57 per cent. of recoveries; and if, finally, Case 12 be also struck out of the list there would be 10 radical operations, 5 of which were successful, giving 50 per cent. of recoveries. Even this result, so far as I know, is much more favourable than the outcome of any previous statistics would show.
2. The question of recurrence.-The gross resalt shown in the foregoing paragraph becomes even more important and pleasing when the question of recurrence is considered. $U p$ to the present moment it is almost universally believed that even if radical operation in malignant disease be for the moment successful a recurrence of disease within a comparatively short time is an almost unavoidable contingency. My results give the most emphatic and incontrovertible denial to this belief that conld be desired. It will be seen from the following tables that in Case 1 the duration of life after operation was six and three-quarter years, the patient finally dying from organic heart disease entirely unconnected with the previous laryngeal affection. In Case 3 the operation was performed five and a half years ago. the patient lives in the best of health, no recurrence having taken place. In Case 5 the operation dates three and a half years back; the patient enjoys the best of health, with no recurrence of the disease. In Case 8 the operation was performed two and a half years ago; the patient at present is perfectly well, with no recurrence of the disease. Case 10 is the only one in which recurrence appears to have taken place, although this cannot yet be stated with absolute certainty. Fears with regared to that point were entertained from the moment of the operation itself owing to the great extent of the disease. If the two doubtful cases, Cases 11 and 12, be also considered in this connexion, the last of them, although the patient is at present perfectly well, has been performed at too recent a date to allow of any conclusions being made with regard to recurrence; but in Case 11 it is now nearly a year and a half since the operation was performed, and there is no trace of recurrence. It will not be questioned, therefore, I think, that with regard to recurrence my results are of the most encouraging character possible, and this the more so if it be considered that most of them have been obtained by operations which only a few years ago were believed by those most competent to judge to be altogether insufficient to eradicate the disease.

3. Phonatory results. - Hqually pleasing and, indeed, surprising are the results which were obtained so far as phona. tion is concerned, and although there can be no doubt that these results are entirely secondary to the more important questions of preservation of life and absence of recurrence, yet the question of a useful voice for the rest of life is one certainly not to ke treated lightly, particularly in the case of men whose power of breadwinning entirely depends upon the possession of their vocal powers. Now with regard to this point, from the tables it appears that in two only out of the seven cases in which recovery took place no improvement of the voice was obtained. These are Cases 2 and 11 of the tables, but it must not be forgotten that in both these cases there had been total aphonia previously to the operation. In the remaining five cases the vocal result was simply surprising. In Case 1 (that of the late Mr. Montagu Williams) it is well known that for five years and a half after the operation-i.e., until the time when his progressive heart affection compelled him to give up work altogether-he was able to fulfil the trying duties of a police magistrate, and this although the whole left half of the thyroid cartilage, the left arytenoid cartilage, and all the soft parts on the left side of the larynx had been removed. In Case 5 the roice, in spite of the removal of all the soft parts on the left side of the larynx, including the left vocal cord, became so perfectly normal that on both the occasions when I demonstrated the patient publicly (once before the Clinical Society of London and once before the Laryngological Society of London) it seemed almost incredible to many in the audience that the possession of such a voice should be compatible with the absence of all these essential parts. Almost equally good results were obtained in Case 8 in spite of the removal of the whole left vocal cord and the front part of the left arytenoid cartilage; and in Case 10 the amount of voice, although it is hoarse, is positively surprising when it is considered that not only all the soft parts on the right side of the larynx but also the anterior half of the left vocal cord had to be removed. In Case 12, finally, in which the entire left vocal cord was removed, the voice, although occasionally a little hoarse and weak, is such that nobody who heard the patient speak would think of the absence of so essential a part of the rocal apparatus. It appears to be a benevolent provision of nature that in the cases in which a vocal cord with its neighbourhood is removed, a cicatricial ridge should form just corresponding to the situation of the removed vocal cord, which enables the healthy vocal cord to almost completely close 